\title{
Reflexiones en y para la enseñanza de la historia de la ética*
}

\author{
José Eriberto Cifuentes Medina* \\ Jaime Andrés Torres Ortiz ${ }^{* * *}$
}

Recibido: 7 de noviembre de 2017

Evaluado: 4 de febrero de 2018

Aceptado: 23 de octubre de 2018

Citar como: Cifuentes Medina, J. E. y Torres Ortiz, J. A. (2019). Reflexiones en y para la enseñanza de la historia de la ética. Hallazgos, 16(31), 167186. Doi: https://doi.org/10.15332/s17 94-3841.2019.0031.07

\section{Resumen}

El proceso de enseñanza-aprendizaje de la ética como disciplina, que en la actualidad se torna complejo por la pérdida de sentido y significado, se ha de recuperar en los niveles educativos en busca de escenarios posibles a partir de la didáctica y la pedagogía desde el aula de clase como espacio de reflexión sistemática de contenido y la posibilidad de la praxis que de paso se ha de entrelazar con su devenir histórico. También en el estudio de la ética en su contexto general y a la base de sus principios, así como en su historia como elemento fundante. La preocupación de los docentes en los diferentes niveles del sistema educativo por la enseñanza de la ética ha sido y es continua, y para el presente caso de investigación se ha diseñado una propuesta que se aborda en el proceso de enseñanza de la ética en la educación superior en pregrado. La investigación desde el aula de clase busca resolver problemas de conocimiento para la enseñanza de la ética: sus alcances, limitaciones, retos, desafíos, conceptos epistemológicos y pragmáticos. La experiencia de enseñanza de la ética está en doble sentido dialógico y sistemático, desde la norma y los lineamientos hasta el análisis de las vivencias y se centra en la enseñanza de su historia.

Palabras clave: historia de la ética, enseñanza-aprendizaje.

El artículo hace parte del proyecto titulado "Las tendencias pedagógicas en el proceso de enseñanza y formación sociohumanística y ética en estudiantes de una licenciatura en educación básica", con código SGI de la Universidad Pedagógica y Tecnológica de Colombia, y también como parte del Objeto Virtual de Aprendizaje de Ética y Política.

** Universidad Pedagógica y Tecnológica de Colombia, Colombia. Correo electrónico: joseeriberto.cifuentes@uptc.edu.co

** Universidad Pedagógica y Tecnológica de Colombia, Colombia. Correo electrónico: jaime.torres@uptc.edu.co ORCID: https://orcid. org/0000-0003-3720-2960 


\section{Reflections on and for the teaching of the history of ethics}

\section{Abstract}

The teaching-learning process of ethics as a discipline, which Received: November 7, 2018 at present time becomes complex due to the loss of sense and Evaluated: February 4, 2018 meaning, has to be recovered in educational levels in search of Accepted: October 23, 2018 possible scenarios based on didactics and pedagogy from the classroom as a space for systematic reflection of content and the possibility of praxis that has to be intertwined with its historical evolution. In the study of ethics in its general context and the basis of its principles, also its history as a founding element. The concern of teachers at different levels of the education system for the teaching of ethics has been and is continuous, and for this research case a proposal has been designed that is addressed in the process of teaching ethics in undergraduate superior education. Research from the classroom aims to solve knowledge problems for the teaching of ethics: its scope, limitations, challenges, epistemological and pragmatic concepts. The experience of teaching ethics is in a dialogical and systematic double meaning, from the norm and guidelines to the analysis of experiences and it focuses on the teaching of its history.

Keywords: history of ethics, teaching-learning. 


\section{Reflexões em e para o ensino da história da ética}

Recebido: 7 de novembro de 2017

Avaliado: 4 de fevereiro de 2018

Aceito: 23 de outubro de 2018

\section{RESUMO}

O processo do ensino/aprendizagem da ética como disciplina, que na atualidade torna-se complexo pela perda de sentido e significado, deve-se recuperar nos níveis educativos em procura de cenários possíveis a partir da didática e a pedagogia desde a sala de aula como espaço de reflexão sistemática de conteúdo e a possibilidade da práxis que permite entrelaçar com seu devir histórico. No estudo da ética no contexto geral e a base dos seus princípios, também sua história como elemento fundante. A preocupação dos docentes nos diferentes níveis do sistema educativo pelo ensino da ética tem sido e é continua, e para o atual caso de pesquisa tem se desenhado uma proposta que se aborda no processo de ensino da ética na educação superior na graduação. A pesquisa desde a sala de aula procura resolver problemas de conhecimento para o ensino da ética: seus alcances, limitações, desafios, conceitos epistemológicos e pragmáticos. A experiência do ensino da ética está em duplo sentido dialógico e sistemático, desde a norma e as diretrizes até a análise das moradias e se foca no ensino da sua história.

Palavras-chave: história da ética, ensino-aprendizagem. 


\section{INTRODUCCIÓN}

Los recursos para la enseñanza de la historia de la ética son importantes en el proceso de enseñanza-aprendizaje durante la educación básica primaria, secundaria y media vocacional, según la Ley 115/1994, de 8 de febrero, por la cual se expide la ley general de educación. Entre las asignaturas obligatorias y fundamentales está la Educación Ética y Valores Humanos (art. 29).

En la perspectiva de la experiencia, abordar la historia de la ética desde la óptica constructivista en pro de la construcción de recursos didácticos para que la enseñanza y el aprendizaje sean más afables, pero, ante todo, más cercanos y familiares para el docente y el estudiante, de manera que no solo contribuya al desarrollo de un plan de estudios preestablecido, sino que también aporte a la formación del ser humano sujeto racional y al desarrollo del pensamiento creativo, metódico, razonado, ordenado, abstracto, meditativo, deliberativo, al igual que a una formación sólida como persona y para vivir en sociedad.

El propósito de este artículo es hacer un recorrido por las cuatro grandes épocas de la historia, teniendo como eje fundamental y columna vertebral la ética y su constitución, aportes y autores en cada aparte de la línea del tiempo. El recorrido desde la época antigua, pasando por la medieval, moderna y llegando a la contemporánea, permitirá dilucidar la importancia de esta para la sociedad humana.

\section{Historia de la ética en la EDAD ANTIGUA Y MEDIEVAL}

Los postulados de la ética en la edad antigua a partir del mundo homérico conlleva revisar la ética desde sus orígenes a fin de consolidar los planteamientos que han perdurado a lo largo del tiempo y otros que han quedado solo en la cultura de origen y también que se han proyectado a otras épocas y culturas.

\section{Generalidades de historia de la ética antigua y medieval}

Después de analizados los elementos fundantes de la ética en los subtemas del tema uno, nos corresponde estudiar cómo muchos problemas cobraron expresión en las diversas doctrinas o teorías éticas que los filósofos y pensadores fueron desarrollando a lo largo de la historia. Como criterio sencillo para estudiar las doctrinas éticas, es la clasificación histórica, dividida en cuatro grandes épocas: antigua, medieval, moderna y contemporánea (tabla 1 ).

A lo largo de la historia, se han propuesto diversos modelos éticos que han intentado dar respuesta a la pregunta ¿cómo ser feliz? Pues la felicidad siempre ha sido entendida como el bien último al que está llamada la existencia humana. Esta respuesta se ha intentado dar desde varias perspectivas fundamentales, sin que ellas agoten el extenso campo que puede estudiar la ética.

El estudio de la ética en las diversas épocas de la historia permite evidenciar la consolidación del pasado, presente y futuro de la 
Tabla 1. Épocas de la historia

\begin{tabular}{ll}
\hline Época & Descripción \\
\hline Antigua & $\begin{array}{l}\text { Periodo histórico entre el siglo VII a. C. aproximadamente y hasta el siglo IV d. C. } \\
\text { La ética en la antigüedad se estudia de manera breve desde el mundo homérico, pa- } \\
\text { sando por los sofistas o presocráticos llegando a la ética griega clásica con Sócrates, } \\
\\
\text { Platón y Aristóteles. Finalmente la ética helenístico-romana con el neoplatonismo, el } \\
\text { epicureísmo, el estoicismo, el escepticismo, entre otros. }\end{array}$ \\
\hline Medieval & $\begin{array}{l}\text { La ética medieval parte desde el periodo de la patrística con san Agustín, santo To- } \\
\text { más, es decir, el periodo histórico entre el siglo V hasta el siglo XV d. C., enmarcada } \\
\text { por el pensamiento cristiano católico y protestante. }\end{array}$ \\
\hline Moderna & $\begin{array}{l}\text { Periodo aproximadamente desde el siglo XV hasta el siglo XVIII con la ética del Re- } \\
\text { nacimiento, de la Ilustración y la ética especialmente de la filosofía alemana: desde }\end{array}$ \\
\hline Kant hasta Hegel y Herbart. \\
\hline Contemporánea & $\begin{array}{l}\text { Comprende el periodo histórico de los siglos XIX a XX. Con diversidad de postula- } \\
\text { dos, planteamientos con autores como Freud, Scheler, Piaget, Adela Cortina y otros } \\
\text { de transcendencia significativa. }\end{array}$ \\
\hline
\end{tabular}

Fuente: Elaboración propia según Escobar (2000).

aplicación de la ética. También se ha tomado el término "ética" para designar los aspectos relativos al buen obrar de las personas dentro de su profesión. El estudio de la historia de la ética permite comprender su desarrollo histórico desde los planteamientos, postulados y autores, al igual que ser estudiada dentro de cada carrera, dado que cada profesión tiene una ética particular y cada profesional debe responder y comportarse como una persona ética dentro de su campo laboral.

\section{Historia de la ética en la edad antigua}

En el desarrollo histórico de la humanidad, se resalta la división por épocas: antigua, medieval, moderna y contemporánea; ahora se estudia y reflexiona en la primera cuando se resalta la preocupación por el comportamiento humano; no brota de la reflexión, del pensamiento que interpreta la experiencia, sino que se solidifica en las obras y en la actividad de los hombres. En la edad antigua, se vislumbra la ética desde varias perspectivas: el mundo homérico, los sofistas y Sócrates, Platón, Aristóteles y la ética de la polis, los estoicos, Epicuro y su jardín.

En la perspectiva del mundo homérico, se proyecta el ethos en relación con somos lo que hacemos como resultado de obras sancionadas por un cierto valor, una cierta utilidad para facilitar la convivencia: armonía de tensiones opuesta, en busca de conjuntamente destensar su oposición. La escritura se convierte en una aliada de la ética, como sucede en la Ilíada y la Odisea como riqueza de comprensión del ethos.

En la relación con los sofistas como hombres cultos y propagadores de la cultura, "en la vida práctica y en el cultivo del arte, conscientes de que las cosas sensibles son modificadas y transformadas por la actividad humana, así también el contenido del espíritu, lo mentado, lo conocido, es removido de un lado para otro y se toma objeto de la atención, y esta atención se torna interesante por 
sí" (Camps, 2002, p. 35). Entre los sofistas más destacados, están Protágoras, Gorgias, Pródico, Hipias, Trasímaco, Antifonte y Critias, quienes con su perspectiva filosófica han consolidado principios y planteamientos en relación con la ética (tabla 2).

La historia de la ética griega se da, en primer lugar, con los sofistas o sabios y, luego, con Sócrates, periodo conocido como antropología de la filosofía griega, y su pensamiento se caracteriza por su rechazo a la tradición cosmológica y su interés por el hombre. En los presocráticos, la ética es todavía incipiente, ya que se interesan preferentemente por investigar la realidad física o natural.

La ética en la edad antigua, como se evidencia en la tabla 3, permite confrontar el inicio de la preocupación del hombre por preguntarse por el hombre. Sócrates indica en una de sus frases célebres "conócete a ti mismo". La frase permite que se haga un análisis del hombre a sí mismo, que se puede considerar como punto de inicio de la ética en relación con el hombre como ser racional y diferente de los demás seres de la naturaleza, que no necesitan comportarse de manera ética o moral ante los demás, sino que su existencia está demarcada por su instinto de supervivencia.

\section{Historia de la ética en la Edad Media}

En el recorrido de la historia como un elemento de retrospección de varias generaciones, se destaca en la cultura occidental el cristianismo y la filosofía moral cristiana, la cumbre de la Edad Media, la ética protestante, el humanismo y la ética y la filosofía en el Renacimiento: Maquiavelo y las utopías.
El cristianismo representa una etapa decisiva en la historia del pensamiento humano. Su importancia radica en que trae consigo una nueva concepción del hombre y del mundo. En sus orígenes, el cristianismo no es una filosofía, es solo una religión distinta de todas las anteriores procedente del judaísmo; una religión revelada por Dios $y$, por consiguiente, la única que pretende

encerrar la verdad absoluta; una religión frente a la cual las demás no son sino manifestaciones espurias. Lo que pude llamarse ética cristiana es bastante complejo, el cristianismo comprende una diversidad de interpretaciones [...], lo imprescindible de la ética cristiana es la creencia en un ser divino (Dios), que es el garante de la virtud y la perfección. (Escobar, 2000, p. 155)

En la patrística, y como principal representante de los padres de la Iglesia, san Agustín, cuya ética está inspirada como todo su pensamiento en la filosofía platónica; su imperativo ético fundamental es "ama y haz lo que quieras". La ética de santo Tomás se encuentra especialmente en las dos divisiones de la segunda parte de la Suma teológica y en el libro tercero de la Suma contra los gentiles en la que toca problemas éticos relativos al fin y los valores morales, a la obligación y a la conciencia. Todos los seres tienen un fin prefijado: el objeto propio de la voluntad es el fin y el bien; por consiguiente, todas las acciones humanas, necesariamente, se ordenan a su fin y el ser se perfecciona en busca de su fin natural, lo que acarrea la felicidad, y como bien o fin último del hombre es Dios. 
Tabla 2. Historia de la ética en la antigüedad

\begin{tabular}{ll}
\hline Corriente o autor & Resumen \\
\hline \multirow{3}{*}{ Mundo homérico } & $\begin{array}{l}\text { La ética se definirá como “somos lo que hacemos”, este hacer, que es la condición } \\
\text { fundamental que define el sentido de un comportamiento, constituye su ontología } \\
\text { moral. Pero el hacer no brota como consecuencia de un contraste con normas, man- } \\
\text { datos, teorías que sirviesen para habilitar las acciones, justificarlas y sancionarlas. }\end{array}$ \\
& $\begin{array}{l}\text { Sigo V a. C. (450-400 a. C.) representado por Protágoras, Hipias de Elis, Gorgias, } \\
\text { entre otros. Los sofistas fueron los hombres cultos de la Grecia de entonces y los } \\
\text { propagadores de la cultura. La felicidad es eudaimonia, que implica la presencia de } \\
\text { un demonio, guardia bueno, que hace la vida próspera y placentera. }\end{array}$ \\
\hline & $\begin{array}{l}\text { Sócrates de Atenas (469-399 a. C. -segunda mitad del siglo V). Fue el primero que } \\
\text { hizo descender la filosofía del cielo y le buscó acomodo en las ciudades, e incluso } \\
\text { la introdujo en los hogares, y la obligó a meditar sobre la vida y las costumbres, } \\
\text { sobre los bienes y los males. La felicidad no está en las cosas externas, sino en el } \\
\text { alma, esencia humana. Hay una faceta esencial de Sócrates como educador que le } \\
\text { contrapone a los sofistas; ellos ofrecen un saber, Sócrates lo busca. }\end{array}$ \\
\hline
\end{tabular}

Platón nació en Atenas (427-447 a. C.; su verdadero nombre Aristocles). El bien como aspiración fundamental de los seres humanos se realiza por la aspiración de las personas al mundo inteligible. Los diálogos que tratan de dar la definición de

Platón una virtud determinada son breves y tienen una estructura muy parecida: en el Lisis se trata de la amistad, en el Laques del valor, en el Carmides de la prudencia o sensatez moral, en el Eutifrón de la piedad, en el Hipias mayor se intenta definir la belleza.

Aristóteles nació en Estagira (384 a. C.). Lo propio de la virtud es el justo medio. Ser virtuoso implica ser bueno y esto, a su vez, implica ser feliz. Aristóteles afirma que

Aristóteles por medio de la memoria se engendra la experiencia en los hombres y en la Ética nicomaquea se justifica que los jóvenes pueden ser matemáticos pero no prudentes, porque la prudencia se refiere a las cosas particulares y concretas, y brota de la experiencia, cosa que el joven no puede tener, porque se requiere la experiencia.

El fundador de esta corriente fue Epicuro de Samos (342-270 a. C.). La ética de Epicuro presenta un eudemonismo hedonista, considera que el placer es el medio que

Epicuro permite alcanzar la felicidad, último bien del hombre: el placer como ausencia del dolor. La verdadera felicidad consiste en la ausencia de dolor en el cuerpo (aponía) y la carencia de perturbación en el alma (ataraxia).

Corriente fundada por Zenón (366-264 a. C.). La felicidad se alcanza viviendo según la naturaleza. El bien es todo aquello que incrementa el logos y el mal aquello

Estoicismo que lo perjudica. Las fuentes coinciden en que Zenón buscó en la filosofía soporte para la vida moral y, cuando entendió necesario que la filosofía se elaborase como sistema, concibió este como dirigido a y culminado en un saber para ordenar la conducta; como suele decirse, un sistema de finalidad ética.

Escepticismo

La felicidad implica despojarse completamente de lo humano, realizando aquella naturaleza de lo divino y del bien, llegando a la impasibilidad del sabio.

Fuente: Elaboración propia según Camps (2002). 
Tabla 3. Historia de la ética en la Edad Media

\begin{tabular}{ll}
\hline Parte o autor & Resumen \\
\hline & La moral es, pues, una dimensión en la religiosidad cristiana. Los relatos de \\
& los Evangelios ponen en labios tanto enseñanzas concretas relativas a aspec- \\
& tos particulares de la vida humana (repudio de la mujer, venganza, riqueza, \\
& valor de los ritos) como otras de alcance general sobre lo que Dios pide al \\
El cristianismo y la filoso- & hombre. Hay que saber comprenderlas en un doble contexto. Jesús enseña, \\
fía moral cristiana & desde la perspectiva del decálogo y de los preceptos del Antiguo Testa- \\
& mento, que no ha venido a abolir la Ley, sino a llevarla a su cumplimiento; \\
& la preocupación de Jesús es por lo esencial del ser humano. El germen de \\
& una filosofía moral cristiana es el Evangelio con ayuda de los aportes de las \\
& cartas paulinas.
\end{tabular}

San Agustín (354-430 d. C.). Él no desarrolla sistemáticamente la ética en ninguna de sus obras. La inspiración inmediata de la doctrina moral agusti-

La cumbre de la Edad niana se encuentra en la Biblia. También con el apoyo de los textos sagrados Media: la moral de san Agustín teniendo en cuenta la tradición teológica y las apreciaciones realizadas por la ciencia cristiana de la patrística; ha de tenerse en cuenta la filosofía en especial platónica. Finalmente, fija la razón de la filosofía en la búsqueda de la felicidad y en eso coinciden los paganos y cristianos.

Santo Tomás (1225-1274). Una recta concepción del hombre orientará en la solución de ese problema. Tal concepción venía deparada también por los sabios griegos. El mundo está regido por la razón. Entre las facultades del hombre, es la razón la facultad rectora. El hombre es animal racional.

Santo Tomás en la escolástica Informado de la racionalidad llevará en consecuencia sus posibilidades de vida a la perfección que le es debida según su naturaleza. La vida moral será buena si secunda el imperium de la razón natural. El objeto de la ética o filosofía moral es la consideración de las operaciones humanas en cuanto ordenadas entre sí y al fin.

Lutero indica que el uso moral de la Ley es el de demandar a los hombres La ética protestante que procuren ser justos, no tanto para con Dios, lo que es imposible, pero sí para con los hombres, y así hacer posible la convivencia y la sociedad civil.

En el último cuarto del siglo XV, y en el primer cuarto del siglo XVI, entre el cierre de la Edad Media y los albores de la Edad Moderna, transcurre la vida de Nicolás Maquiavelo y Tomás Moro. Se da una reflexión del Estado

La filosofía en el Renacimiento: Maquiavelo y las utopías y la política, la moral, excepto en la medida en que es la acción política o resulta políticamente relevante. El ser humano es siempre el mismo como es siempre idéntica la naturaleza en general y en consecuencia también lo son la historia y la política.

Fuente: Elaboración propia según Camps (2002).

\section{Principales modelos de la ética en la edad antigua y medieval}

Son innumerables los sistemas y modelos éticos elaborados a lo largo de la historia. Al estudiar diferentes modelos éticos, se amplía en el estudio de diversos filósofos, pensadores, se encontrarán planteamientos diferentes, algunos enfrentados y quizá se terminará por comprender la ética como un polifacético abanico de teorías sobre la moralidad (tabla 4).

La ética se asimila a obrar con honestidad, con rectitud y con compromiso, o a obrar con y en justicia, o lo que es lo mismo de acuerdo con las leyes. Santo Tomás desarrolla la teoría de las virtudes dentro de la teología 
Tabla 4. Principales modelos éticos

\begin{tabular}{|c|c|}
\hline Modelo & Breve descripción \\
\hline Ética de virtudes & $\begin{array}{l}\text { En nuestra sociedad, de tradición occidental y cristiana, está fuertemente enraizada } \\
\text { en el modelo ético del hombre virtuoso. La máxima aspiración del hombre consiste } \\
\text { en la felicidad, que no puede encontrarse sino en Dios, fin último de la vida humana. } \\
\text { Y esa felicidad se alcanza mediante el ejercicio de las virtudes. El origen de esta ética } \\
\text { se encuentra en los griegos. Los grandes clásicos de la filosófica griega: Sócrates, } \\
\text { Platón y Aristóteles, son sus máximos representantes. Veamos cómo la presenta } \\
\text { Aristóteles, cuya Ética a nicómaco es sin duda el libro de ética más importante de la } \\
\text { antigüedad. El hombre está orientado por su naturaleza hacia la felicidad. El nombre } \\
\text { griego de felicidad (eudaimonia) hace que este sistema ético se denomine también } \\
\text { eudemonismo: la felicidad. }\end{array}$ \\
\hline
\end{tabular}

Epicureísmo $\quad$ El placer constituye una aspiración generalizada entre los hombres de todos los tiempos. Vivir rodeado de placeres y satisfacciones es el ideal que la sociedad de consumo difunde a través de los medios de comunicación en la actualidad. La teoría que desarrolla esta tendencia como criterio último de moralidad es denominada hedonismo. La antigüedad tiene su máximo representante en Epicuro, hombre de una gran personalidad, admirado y seguido en su tiempo por numerosos discípulos. Para Epicuro, el principio de todo bien se halla en el placer. El placer que hace verdaderamente dichoso al hombre es un placer tranquilo, equilibrado. El placer puro es aquel que no lleva mezcla de sufrimiento. Tal placer deja un recuerdo agradable que hace desear la repetición. Saber seleccionar los placeres y saber calcular su medida, con el fin de eliminar lo más posible el sufrimiento, sería la máxima de la actividad moral que brinda el epicureísmo a los hedonistas de todos los tiempos.

Estoicismo El estoicismo es una escuela filosófica contemporánea y antagónica de la anterior. Recibe su nombre de la stoa o pórtico, donde Zenón reunía a sus primeros discípulos a comienzos del siglo IV a. C.

Los representantes son Epicteto, Séneca y Marco Aurelio. Los planteamientos son de carácter moral. En los cimientos del estoicismo, se halla la comprensión del mundo como cosmos, un orden universal, un orden universal, regido por las leyes inmutables que gobiernan también la vida humana. El ideal del hombre consiste en vivir conforme a la naturaleza. El camino de la perfección reside en la apatheia, una actitud de indiferencia positiva frente a los acontecimientos. Para alcanzarla, el hombre debe comenzar por cultivar la ataraxia o imperturbalidad. El no dejarse turbar por nada, sea agradable o desagradable, nos garantiza la tranquilidad de espíritu, en armonía total con la naturaleza. Todo lo que nos sucede: éxitos, alegrías, sufrimientos, muerte, es lo que nos conviene. Aceptarlo, sin apego y no resistencia, es alcanzar la perfección y la felicidad; a esta actitud se le une la conciencia de la dignidad humana.

Neoplatonismo Esta corriente es marcadamente religiosa y recoge la tendencia mística del hombre a sumergirse en la divinidad. Ya el ideal de la vida propuesto por Platón para alcanzar la felicidad resaltaba el cultivo de la sabiduría mediante la contemplación y la mortificación de todos los deseos sensuales que provienen del cuerpo, la parte inferior y perecedera del hombre.

Plotino, desarrollando el esquema del idealismo platónico, elabora toda una metafísica religiosa que influirá decisivamente en la ascética cristiana hasta mediados del siglo $\mathrm{XX}$ y que aún perdura en numerosos grupos religiosos, que siguen colocando la perfección de la vida cristiana en la unión afectiva del alma con Dios. El fundamento o principio supremo de toda realidad es el Uno, que es el ser perfecto, primero, absoluto, de él proviene, por emanación, el nous, inteligencia o espíritu, y de este el alma. El alma del hombre ha sido corrompida al caer y quedar aprisionada en un cuerpo. La búsqueda de la perfección consistirá en una marcha ascendente hacia el Uno.

San Agustín La felicidad depende del bien. El bien moral es obrar en sintonía con el sumo Bien, mientras que el mal es simplemente ausencia de bien. 


\begin{tabular}{ll}
\hline Modelo & Breve descripción \\
\hline Boecio & $\begin{array}{l}\text { Todas las cosas se encuentran ordenadas según una norma adecuada a ellas, que las } \\
\text { orienta hacia el bien. }\end{array}$ \\
\hline Pedro Abelardo & $\begin{array}{l}\text { La intención es la base de la conciencia moral y es la que sirve para calificar las accio- } \\
\text { nes de buenas o malas. }\end{array}$ \\
\hline Santo Tomás & $\begin{array}{l}\text { La virtud y la justicia están en el orden de las cosas divinas. Conocer el bien implica } \\
\text { necesariamente obrar el bien. }\end{array}$ \\
\hline
\end{tabular}

Fuente: Elaboración propia según González (2003) y Suárez (2003).

cristiana. En este contexto, él habla de las virtudes teologales: fe, esperanza y caridad. Según este planteamiento, por medio de estas virtudes, las personas logran superar sus apetitos sensibles y comienzan un camino de perfección que las conducirá a su fin último que es Dios, fuente de toda felicidad.

Los modelos éticos permiten impulsar los procesos educativos formales e informales, de los niños y jóvenes de manera particular, nos llevan a tener fe en la construcción de las ciudades y de la vida comunitaria en las áreas rurales y urbanas, desde una perspectiva ética; ganar en confianza en las actividades formativas de los ciudadanos es ganar personas de bien para el progreso personal y social, en pro de una sana y correcta convivencia entre los seres humanos.

Los modelos éticos, no solo son doctrinas o corrientes de pensamiento, sino que han de trascender en la ética ciudadana al reconstruir el saber práctico que permite afinidad a un sentido común para todos los ciudadanos; nos permiten reconocer que nuestras acciones son parecidas a las de los otros y que en la pluralidad puede haber un verdadero encuentro. El reconocimiento de un pluralismo razonable, en lugar de los absolutismos tradicionales, de la información, de la tecnología, de la identidad cultural, del contrato según las mayorías, de acuerdos mínimos, permite crear ciudad, fortalecer el sentido de la participación y enriquecer la interacción social.

El ser humano, y más en la condición de estudiante universitario, está llamado a estudiar los modelos éticos pero aplicarlos en la corresponsabilidad en los proyectos comunes y la responsabilidad social que nos compete. Reconocer la posibilidad de ejercer todas las ciudadanías es un primer paso; de hoy en adelante, la acción diaria, la unidad de vida, que es en realidad la unidad debida, el compromiso real con nosotros, y con los demás, la posibilidad de aplicar la regla de oro: "No hagas a otro lo que no deseas para ti".

\section{Historia de la ética en la Edad Moderna $Y$ CONTEMPORÁNEA}

A lo largo de la historia, y en las diferentes culturas, las personas siempre han buscado una forma específica de orientar su vida, de realizar la misión a la que se sienten llamados en el mundo o desarrollar lo que consideran que es su vocación. En este sentido, se han presentado diversas propuestas que permiten orientar las acciones humanas, por lo que se puede establecer con claridad que una es mejor que la otra, pues esto depende de los contextos y de las situaciones 
particulares de la vida. Así, cada persona debe ponderar las diferentes formas de vida y las distintas teorías al respecto, y luego apropiarse de aquello que cree convenientemente para su realización.

\section{Historia de la ética en la Edad Moderna}

Una nueva y fructífera etapa de la historia de la ética adviene con la modernidad, que inicia en el Renacimiento (siglo XV) y se prolonga hasta finales del siglo XVIII y principios del siglo XIX. A diferencia de la ética medieval, esencialmente teocéntrica y teológica, la ética moderna se caracteriza por su antropocentrismo: la tendencia a considerar al hombre como centro de todas las manifestaciones culturales: política, arte, ciencia, moral, etc. En el Renacimiento, surge el humanismo que trata de reivindicar al hombre, concibiéndolo como ser autónomo y radical. La época moderna presenta rasgos tan decisivos (tabla 5).

Pensadores como san Agustín, en la Edad Media, en cuyas letras respira el hombre interior, el hombre angustiado ante hondos conflictos humanos; pensadores como Blas Pascal en la Edad Moderna, que puso de relieve la importancia del sentimiento sobre la razón; el corazón y no la razón es el que siente a Dios; o bien filósofos de la genialidad de Friedrich Nietzsche, que se lanza a conquistar la realidad vital del hombre. La filosofía existencialista de la Edad Contemporánea se caracteriza, entonces, por afirmar que la existencia precede a la esencia, lo que significa que el hombre empieza a existir, se encuentra, surge en el mundo, y después se define. Señala Sartre que el hombre no es definible, porque empieza por no ser nada, por lo que la existencia del hombre se va haciendo. En la ética moderna, se encuentran varios autores y postulados, como Descartes, Spinoza, Leibniz, Hegel, Schopenhauer y Kant quien trabaja la doctrina moral creada en el siglo XVIII (tabla 6).

En relación con éticas autónomas y heterónomas de Occidente, conlleva realizar un análisis de la autonomía y heteronomía. La heteronomía se define como el comportamiento de una persona que siempre se ha

Tabla 5. Generalidades de la ética en la Edad Moderna

\begin{tabular}{ll}
\hline Aspecto & Breve descripción \\
\hline Social & $\begin{array}{l}\text { Puede mencionarse la creación y el fortalecimiento de una nueva clase social: la burgue- } \\
\text { sía, en la que el banquero, el comerciante, el industrial, reemplazaron al terrateniente, al } \\
\text { eclesiástico y al guerrero como tipos de influencia social predominante. }\end{array}$ \\
\hline Científico & $\begin{array}{l}\text { La ciencia reemplaza la religión y se convierte en factor principal de la nueva mentalidad } \\
\text { humana. }\end{array}$ \\
\hline Filosófico & Surge, acorde con los nuevos tiempos, una filosofía eminentemente racionalista. \\
\hline Político & $\begin{array}{l}\text { Se logran crear los Estados modernos, fragmentándose, de este modo, la vieja sociedad } \\
\text { feudal. }\end{array}$ \\
\hline Religioso & $\begin{array}{l}\text { En el aspecto religioso, la Iglesia deja de ser el poder central. Así, señala Laski que, en la } \\
\text { época moderna, “la Iglesia, tal como estaba organizada, era considerada un verdadero } \\
\text { estorbo para la implementación del nuevo orden social”. }\end{array}$ \\
\hline
\end{tabular}

Fuente: Elaboración propia según Escobar (2000). 
Tabla 6. Historia de la ética en la Edad Moderna

\begin{tabular}{|c|c|}
\hline Autores & Resumen \\
\hline Descartes & $\begin{array}{l}\text { Esforzarse más es vencerse a sí mismo más que a la suerte, y por cambiar los deseos } \\
\text { personales más bien que el orden del mundo. }\end{array}$ \\
\hline Leibniz & $\begin{array}{l}\text { Vivimos en el mejor de los mundos posibles. El mal moral se produce cuando el ser } \\
\text { humano renuncia a los fines para los cuales está destinado. }\end{array}$ \\
\hline Hobbes & $\begin{array}{l}\text { Es creador de la filosofía política y de la filosofía social como ciencia. En cuanto a la ley } \\
\text { natural, esta sería el precepto obtenido mediante la razón en orden a preservar la propia } \\
\text { vida. En el Leviatán, Hobbes enumera hasta dieciséis leyes naturales, de las cuales las más } \\
\text { significativas se refieren al mandamiento de la paz, a la legítima defensa y al respeto de } \\
\text { los pactos. }\end{array}$ \\
\hline Espinoza & $\begin{array}{l}\text { Sus tres obras más importantes se titulan Ética, Tratado teológico-político y Tratado político. } \\
\text { Su obra Ética, en la primera parte, "De Dios", trata de fundamentales cuestiones metafísi- } \\
\text { cas; la segunda, "De la naturaleza y el origen del alma", y la tercera, "Del origen y natura- } \\
\text { leza de los afectos", se constituyen en una especie de tratado de psicología; y en la cuarta } \\
\text { parte, "De la servidumbre o de la fuerza de los afectos en la que empieza", se habla de } \\
\text { bien, mal, fin, virtud, es decir, nociones ordinariamente asociadas a la filosofía moral. La } \\
\text { ética se explica y se vive de acuerdo con los caracteres de la geometría. El conocimiento es } \\
\text { la verdadera potencia que libera al ser humano de las pasiones. }\end{array}$ \\
\hline Locke & $\begin{array}{l}\text { Locke aborda el conocimiento moral en el que indica hasta qué punto y de qué manera los } \\
\text { humanos son capaces de conocer la ley natural, puesto que el conocimiento humano es } \\
\text { limitado y deficiente. Dios ha de ser el fundamento último de la ley natural. En cuanto al } \\
\text { hombre, ha de desconfiar de las opiniones y tradiciones recibidas, los contenidos de esa ley. } \\
\text { La ética se ocupa de grandes cuestiones: problemas de fundamentación y legitimación, } \\
\text { primeros principios, razones últimas de la obligación moral. La moral, en cambio, se } \\
\text { refiere a las costumbres, a las formas de ser aconsejables para una mejor convivencia. }\end{array}$ \\
\hline Montesquieu & $\begin{array}{l}\text { Por naturaleza, el hombre es un ser moral, que no puede vivir sin unos principios signi- } \\
\text { ficativos que orienten su acción, y precisamente en esa realización de su naturaleza con- } \\
\text { sidera Montesquieu que radica la felicidad. La paradoja es que, por un lado, los hombres } \\
\text { no pueden vivir sin normas éticas, y que ese cumplimiento de las normas, esa virtud, o es } \\
\text { espontánea o no lo es; pero, por otro, la naturaleza humana tiende al egoísmo y a satisfa- } \\
\text { cer sus propios deseos por encima de las obligaciones morales con el prójimo. }\end{array}$ \\
\hline Hume & $\begin{array}{l}\text { La moralidad es una cuestión práctica, es decir, mueve a la acción; la razón, en cualquiera } \\
\text { de sus dos operaciones, es incapaz de causas de acción; por tanto, la moralidad no es una } \\
\text { cuestión de la razón exclusivamente. }\end{array}$ \\
\hline Schopenhauer & $\begin{array}{l}\text { El pensamiento está todo orientado a buscar un remedio eficaz contra el sufrimiento y la } \\
\text { desolación de la vida. La moral, es decir, la sección práctica de su filosofía, no es un apén- } \\
\text { dice sino la razón misma del sistema. Su punto de partida es una intuición supremamen- } \\
\text { te clara e indiscutible. Si los hombres llevaran una vida feliz o al menos no patentemente } \\
\text { miserable, jamás se les ocurrirá algo tan embarazosamente antinatural como ponerse a } \\
\text { pensar. La vida ética está en la compasión, en el hecho de reconocer en el otro el dolor } \\
\text { propio y evitarlo a toda costa. }\end{array}$ \\
\hline
\end{tabular}

Uno de los máximos responsables de que hoy identifiquemos la ética con la autodeterminación y reservemos para la estética o la religión el cumplimiento de una más satisfactoria autorrealización del sujeto. La vida ética no solo consiste en adoptar la norma, en lo Kierkegaard universal que nos hace autónomos, sino en someterla a un hábito, a una repetición sin la cual ni hay tarea moral que se cumpla ni, esencialmente, sujeto moral que se precie de su individualidad. Lo ético, que no es ni mucho menos monotonía, es lo que permite al individuo subsistir en el tiempo y conservarse como tal, en lugar de detenerse en una abstracta e impersonal autodeterminación. 


\begin{tabular}{|c|c|}
\hline Autores & Resumen \\
\hline Kant & $\begin{array}{l}\text { Debemos actuar pensando que nuestra norma de comportamiento pueda convertirse } \\
\text { en ley universal. En el siglo XVIII, Kant elabora un nuevo modelo ético, que busca un } \\
\text { fundamento diferente para la vida moral. Las éticas anteriores tenían un fundamento } \\
\text { heterónomo, es decir, fundamentaban sus exigencias o principios en realidades exteriores } \\
\text { y trascendentales al hombre mismo: Dios, la idea del bien, la naturaleza, la felicidad. El } \\
\text { interés de Kant consiste en darle a la moral un fundamento autónomo: que la moralidad } \\
\text { misma del hombre constituya el fundamento último y la fuente original de todas las } \\
\text { normas morales. Esto equivale a decir en un lenguaje sencillo: no importa si el objetivo } \\
\text { de mi acción es en sí mismo bueno o malo, lo importante es la intención que me mueve a } \\
\text { realizarla. } \\
\text { Kant sintetiza el principio práctico del obrar moral en la siguiente máxima: “Obra siem- } \\
\text { pre de tal manera que la máxima de tu voluntad pueda valer como principio de legisla- } \\
\text { ción universal". }\end{array}$ \\
\hline Marx & $\begin{array}{l}\text { El individualismo ético es el punto de vista según el cual solo existen sujetos éticos indi- } \\
\text { viduales y ninguna colectiva tiene relevancia ética en tanto que sujeto. Marx no elaboró } \\
\text { ninguna filosofía moral, sino que se ocupó de los problemas éticos. Marx denuncia la } \\
\text { moral junto con la religión y la filosofía como formas de ideología tras las cuales solo } \\
\text { existen los intereses de las clases dominantes; y por otro lado, toda su crítica radical del } \\
\text { capitalismo por su naturaleza explotadora, alienante e injusta con la mayoría y particular- } \\
\text { mente con los más débiles. }\end{array}$ \\
\hline Nietzsche & $\begin{array}{l}\text { En Genealogía de la moral, trazó los rasgos esenciales del proceso que ha seguido la evo- } \\
\text { lución ética dentro de ese marco inesquivable de autoafirmación grupal. Los primitivos } \\
\text { creadores de valores fueron seres fuertes, intrépidos, orgullosos de sí mismos y por ello } \\
\text { llamaron bueno a lo que se les parecía y malo a lo que despreciaban. La moral de los } \\
\text { esclavos ha prevalecido durante los siglos anteriores. Ahora debe prevalecer la moral de } \\
\text { los señores; el superhombre determina su propia moral. }\end{array}$ \\
\hline Hegel & $\begin{array}{l}\text { La ética adquiere el carácter de eticidad, en la que el valor moral de los actos radica en la } \\
\text { relación entre estos y su comunidad. }\end{array}$ \\
\hline Sartre & $\begin{array}{l}\text { Actuar en libertad implica la elección del propio ser. Ser libre conlleva asumirse desde su } \\
\text { propia realidad, reconocerse como nada. }\end{array}$ \\
\hline Habermas & $\begin{array}{l}\text { Las normas morales válidas son fruto de la argumentación consensuada dentro de una } \\
\text { comunidad ideal de vida. }\end{array}$ \\
\hline
\end{tabular}

Fuente: Elaboración propia según Suárez (2003).

de regir por condicionamientos externos a sí misma y a su razón. Kant fue el primer filósofo en determinar el comportamiento moral según la autonomía, en total oposición a la heteronomía; se trata de fundamentar el comportamiento de las personas según una norma no impuesta desde fuera, cuyo comportamiento moral obedeciera a sus propios criterios y al buen uso de la razón.

Para Kant, la ley moral debía ser de tipo formal, "que se prestaba como un imperativo categórico, que consiste en una ley cuya validez universal se da gracias a su racionalidad. Para dicho imperativo categórico (Suárez, 2003, p. 62), Kant establece tres formulaciones:

- Obra (actúa) de modo que la máxima que tu voluntad tenga siempre validez, al mismo tiempo, como principio de una legislación universal.

- Obra (actúa) de modo que consideres a la humanidad, tanto en la persona de 
todos los demás, siempre como fin y nunca como simple medio.

- Obra (actúa) de modo que la voluntad, con su máxima, pueda considerarse como legisladora universal con respecto a sí misma.

Es claro que, cuando las personas actúan por puro deber, se vuelven dignas de felicidad, lo que implica una consecuencia de la actuación y no solo la finalidad en sí misma.

\section{Historia de la Edad Contemporánea}

Se terminará este panorama de la historia de la ética con algunas de las principales corrientes contemporáneas: siglos XIX y XX. En realidad, es difícil determinar los límites cronológicos y el sentido fundamental del pensamiento contemporáneo, entre otras razones, porque es un pensamiento que aún se está gestando y desenvolviendo, y porque, estando ubicados en la atmósfera intelectual que él forma, falta la perspectiva adecuada para abarcarlo y juzgarlo cabalmente.

El estudio de la ética contemporánea que haremos se referirá a corrientes, autores, planteamientos de los siglos XIX y XX: Freud y la génesis de la conciencia moral, Scheler y la ética de los valores, la psicología moral de Piaget y la psicología moral de Kohlberg, la ética discursiva de Adela Cortina que destaca el aspecto concreto del hombre: hombre de carne y hueso (tabla 7).

Desde las últimas décadas del siglo $\mathrm{XX}$ y hasta hoy, se ha mantenido un nuevo modelo de interpretación y de fundamentación de la moral, denominado ética dialógica. Este tipo de ética se basa en la búsqueda de consensos que permitan asumir acuerdos morales dentro de una comunidad. El planteamiento pretende ser capaz de universalizar normas para uno o más grupos humanos a través de la argumentación. Del mismo modo, propone un modelo que sirva para determinar las acciones morales válidas para los diversos pueblos y que tenga una aplicación concreta en las diferentes formas de ser de la moral.

\section{Principales modelos de la ética moderna y contemporánea}

Son innumerables los sistemas y modelos éticos elaborados a lo largo de la historia.

Tabla 7. Historia de la ética en la Edad Contemporánea

\begin{tabular}{ll}
\hline Parte o autor & Resumen \\
\hline & Los problemas concernientes a la moral, en un sentido naturalmente amplio, ocu- \\
pan una parte de la obra de Freud. Se ha de advertir que en Freud la operación \\
valorativa, el dar-valor, el valorar un objeto (ya sea otro, ya sea uno mismo, y más \\
concretamente, la acción de uno mismo), no es solo ética sino también estética. \\
Los valores, pues, son para Freud las formas socialmente permisibles de transac- \\
ción pulsional que al sujeto le son factibles verificar en la realidad que constituye \\
la comunidad social. No dejan de ser, por consiguiente, convenciones, si bien \\
la conciencia moral \\
mantenidas históricamente, y por tanto, relativas, aunque acunadas; piensa en \\
una primera etapa, incluso biológicamente. \\
Los valores sociales estéticos y éticos son la única forma permisible, transaccio- \\
nal, de gratificación pulsional, quiere esto decir que valorar es desear, y se valora \\
como se desea, esto es, cada cual valora como desea.
\end{tabular}




\begin{tabular}{ll}
\hline Parte o autor & Resumen \\
\hline & La ética es el conjunto de conocimientos y técnicas adecuadas para adiestrar los \\
componentes de un grupo humano en la práctica de las acciones aprobadas por el \\
grupo. La ética sería la conformación de la conducta, su condicionamiento desde \\
el exterior social, algo parecido a un entrenamiento deportivo de la convivencia. \\
La posición de Scheler es exactamente lo contrario. En el mundo que nos acaba de \\
describir, la ética se refiere, principalmente, a la actitud general del hombre, a su \\
modo de sentir y de pensar, a su ethos o escala de valores. Aunque parezca un jue- \\
go de palabras, hay que decir que un hombre bueno es aquel que en efecto apre- \\
cheler y la ética de prefiere lo que realmente es apreciable y preferible. No se puede plantear la \\
los valores \\
pregunta ¿qué son los valores?, porque los valores no son, sino que simplemente \\
valen o pretenden valer. \\
Los valores se dividen en del agrado, vitales, espirituales (estéticos, jurídicos e \\
intelectuales) y religiosos.
\end{tabular}

Se propuso estudiar exclusivamente la génesis del juicio moral y no las conductas o los sentimientos morales. Para ello, elaboró una metodología clínica, basada en una combinación de observación y entrevista con niños de escuelas. Su hipótesis de partida es la de que toda moral consiste en un sistema de reglas y la esencia

La psicología moral de Piaget

La psicología moral de Kohlberg de cualquier moralidad hay que buscarla en el respeto que el individuo adquiere hacia estas reglas.

Piaget emprendió el estudio de la estructura de la moralidad en el niño, poniendo en claro el papel del influjo adulto sobre el niño, el efecto de la cooperación entre iguales y la incidencia del desarrollo intelectual sobre el juicio moral, poniendo de relieve la interacción entre sí.

Estableció que la génesis del desarrollo moral atravesaba tres niveles: preconvencional, convencional y de principios, en cada uno de los cuales se hacía preciso distinguir los estadios; seis en total.

Nivel A: nivel preconvencional; estadio 1: estadio de castigo y obediencia; estadio 2: estadio de designio e intercambio individual instrumental.

Nivel B: nivel convencional; estadio 3: estadio de expectativas, relaciones y conformidad mutuas interpersonales; estadio 4: estadio de mantenimiento del sistema social y de conciencia.

Nivel B/C: nivel transicional.

Nivel C: nivel posconvencional y de principios; estadio 5: estadio de derechos prioritarios y contrato social o utilidad; estadio 6: estadio de principios éticos universales.

La ética se presenta como deontológica, en la medida en que se ocupa de la vertiente normativa del fenómeno moral y prescinde de las cuestiones referentes a la felicidad y la vida buena. Los enunciados normativos constituyen su objeto, porque componen la dimensión universalizable del fenómeno moral: proyectar ideales de vida buena es cosa de los individuos y los grupos.

La ética discursiva no debería descuidar la dimensión subjetiva de la moralidad para una exterioridad jurídica o sociológica, porque en el mundo moral al cabo los sujetos siguen siendo los individuos y sus opciones. Analizar los móviles, las actitudes, del diálogo intrasubjetivo y la fuerza axiológica del principio ético, además de las peculiaridades externas del procedimiento moral, es tarea urgente para una ética que no se resigne a reducir la moral a derecho. El principio del discurso se refiere al punto de vista de la razón práctica, desde el que es posible juzgar imparcialmente una norma y decidir sobre ella.

Fuente: Elaboración propia según Camps (2002). 
Al estudiar diferentes modelos éticos, se amplía en el estudio de diversos filósofos, pensadores, se encontrarán planteamientos diferentes, algunos enfrentados y, quizá, se terminará por comprender la ética como un polifacético abanico de teorías sobre la moralidad en la Edad Moderna y en la Edad Contemporánea (tabla 8).

Dentro de las corrientes éticas de la Edad Contemporánea, cobra un gran interés para nuestro momento histórico la denominada ética de la liberación, que está inserta en el marco general de una filosofía de la liberación, dada en los países que han sufrido la dominación y la dependencia; es una cuestión ceñida a América que abarca donde haya opresión del hombre por el hombre.

El aspecto ético de esta corriente filosófico-ética plantea una relación de igualdad, fraternidad, solidaridad, pero rechaza los

Tabla 8. Principales modelos éticos

\begin{tabular}{ll}
\hline Modelo & Breve descripción \\
\hline & El utilitarismo es sin duda el modelo ético más seguido en la actualidad. Constituye \\
& un resurgimiento del epicureísmo hedonista en pleno siglo XVIII. Su principio fun- \\
& damental consiste en la felicidad, que se consigue en busca del placer y rechazando el \\
& dolor. Bueno es lo que produce placer; malo es lo que produce dolor. Esto se deduce \\
& del criterio de utilidad, que constituye el móvil último de todas las acciones. Es útil lo \\
& que aumenta el placer y disminuye el dolor. \\
& El primer utilitarista con renombre universal es Betham, un filántropo preocupado por \\
& la felicidad de la humanidad, a cuyo servicio elabora una aritmética moral. La conduc- \\
& ta debe regirse solo por el interés. Toda la sabiduría moral consiste en un frío cálculo \\
& de intereses. El sacrificio, el ascetismo, el desinterés, son ideales falsos. La virtud es el \\
& hábito de hacer bien las cuentas para lograr mayor placer. \\
& Stuart Mill corrige esta doctrina dándole mayor importancia a la calidad del placer \\
& que a su cantidad: “Vale más llegar a decir ser un hombre descontento que un cerdo \\
Utilitarismo & satisfecho". Los placeres intelectuales o del espíritu son más valiosos que los placeres \\
& sensuales. Moralmente, las personas se clasifican de acuerdo con el tipo de placeres a \\
& que aspiran.
\end{tabular}

En los últimos siglos, el hombre occidental, a medida que se independiza de los esquemas de pensamiento del mundo medieval, descubre que los valores morales tradicionales son puras máscaras que ocultan los intereses egoístas de unos y las bajezas y miserias de otros. En este contexto, surge la obra de Nietzsche, cuya influencia ha

Ética del sido considerable en todo el pensamiento contemporáneo. La crisis de valores del siglo superhombre XX es en el fondo un vacío de valores. Y Nietzsche es su máximo testigo, cuya mayor preocupación consiste en el porvenir de la civilización occidental. Los hombres poderosos, muy escasos y solitarios, constituyen una raza superior caracterizada por valores opuestos a los de la raza inferior. Para ellos no existe otra regla moral que el desarrollo de su propia personalidad en vistas al poder y la grandeza. El que realiza en su vida el ideal del hombre poderoso se convierte en un superhombre.

El marxismo se preocupó por elaborar una ética en forma sistemática prácticamente hasta la segunda mitad del siglo XX, tal vez debido a que todo él es una filosofía de profundo carácter moral. Algunos de los principios básicos de la antropología marxista que definen un tipo de ética diferente, como criterio último de verdad, son la praxis,

Ética marxista la acción, la producción, el trabajo, la eficacia histórica, indicadores de la verdad y, por consiguiente, de la bondad moral. La alienación constituye la fuente y la máxima expresión de la deshumanización. Marx propone el ideal del hombre libre, que será el fruto de la sociedad comunista, sin clases. La moral marxista es ante todo una moral revolucionaria. 
En oposición a la ética kantiana, de carácter formal, se desarrolla en la primera mitad del siglo XX una ética preocupada más por el contenido que por la forma de la acción moral. Se trata de una ética axiológica en la que se destacan Scheler y Hartmann. El valor moral de las personas radica en los valores objetivos, de carácter positivo o negativo, que encarnan en su conducta.

Algunos consideran el valor como un ideal, otros lo consideran como una cualidad objetiva que se da en los seres. Los valores plasman ideales de perfección que el hombre capta intuitivamente y frente a los cuales se siente atraído para una realización o Ética axiológica práctica concreta de estos. De la percepción del valor surge el sentido del deber moral. Los valores poseen algunas propiedades: objetividad: valen por sí mismos independiente de la apreciación de cada individuo; objetividad: cada persona tiene su propia percepción estimativa de los valores; cualidad: se distinguen diversas clases de valores: estéticos, morales, religiosos, biológicos, etc.; polaridad: en todo valor, se da una graduación de perfección entre los extremos: positivo o negativo; jerarquía: entre los valores se da un orden de importancia, unos se subordinan a otros; historicidad: están sometidos a los condicionamientos y cambios históricos, lo que les confiere un carácter de relatividad, aunque no de relativismo.

La ética de la liberación parte de la conciencia de la situación de opresión en que se encuentra el pueblo latinoamericano, así como los demás pueblos del tercer mundo.

Ética de la Para la ética de la liberación, el bien moral consiste en la práctica de la justicia que es liberación reconocimiento del derecho del oprimido: el otro. Así, parafraseando a Duseel, el bien ético es el si-al-Otro y, por tanto, es justicia; es cumplir la justicia y respetar al Otro como otro, dejarlo ser. Este sentido ético de alteridad, como perspectiva que ilumina la praxis de liberación, penetra todos los ámbitos de la vida humana.

La ética comunicativa o dialógica ha sido desarrollada en las últimas décadas del siglo XX sobre todo por Apel y Habermas en Alemania. Es una ética formal; preocupados por la justificación y la fundamentación de la ética en una sociedad pluralista y democrática como la actual, colocan el énfasis en el procedimiento para llegar entre todos a una normativa moral universal.

Ética Adela Cortina, en España, ha presentado este modelo de ética como una ética de "rescomunicativa ponsabilidad solidaria". Con estas categorías, responsabilidad y solidaridad, trata de evitar el peligro de quedarse en la pura formalidad del diálogo.

Para hacer posible la ética dialógica, todos los miembros de la comunidad se deben reconocer recíprocamente como interlocutores con los mismos derechos y se deben obligar a seguir las normas básicas de la argumentación, de este modo es posible llegar a establecer unas normas mínimas por consenso, las cuales regularán el comportamiento moral en la sociedad pluralista y democrática.

Fuente: Elaboración propia según González (2003).

populismos, considerando que la política de liberación es aquella hegemonizada por el bloque social de los oprimidos (clase obrera, campesinos, etnias, marginales, etc.). La ética de la liberación se opone al machismo, al sometimiento de la mujer, a la concepción de la mujer como mero objeto sexual. Se trata de una revolución cultural por lo ancestral, lo propio debe rescatarse y desarrollarse dentro del marco de una cultura moderna. La ética de la liberación busca el bien ético del si-al-Otro y, por tanto, es justicia; es cumplir la justicia y respetar al Otro como otro, dejarlo ser.

Se escucha con frecuencia hablar de que vivimos una época crítica que conlleva un derrumbe o deterioro de valores y actitudes; con frecuencia se escucha de padres de familia, docentes y adultos la frase: "Los tiempos pasados fueron mejores", que hubo 
un tiempo dorado como el que han soñado o recreado muchos filósofos de la historia en el que todo parecía mejor porque el ser humano no estaba contaminado por tanta maldad.

Es necesario partir del hecho de reconocer que vivimos, en efecto, una época marcada por la crisis, considerando crisis un trastorno físico que da durante una enfermedad, el cual trasladado al campo de la ética se estaría hablando de un trastorno o malestar moral en que los valores tienen nuevas valoraciones y nuevas formas de entender perdiendo la vigencia y tradición de interpretación; este cambio produce una crisis y un malestar por su nueva comprensión y las nuevas formas de vida.

Recordemos brevemente algunos ejemplos. Posterior a la muerte de Aristóteles, la cultura griega entra en un proceso de descomposición con la llamada filosofía helenístico-romana que consolida. La Edad Media significó la bancarrota de una serie de valores consagrados en la filosofía helenístico-romana como concepciones y valores que conducían a la felicidad y se consolidó el cristianismo con su asiento religioso en la Edad Media, que luego en la Edad Moderna Nietzsche planteará como la transmutación de los valores, y ahora sí era posible alcanzar la verdadera felicidad; y así época por época, en la Edad Contemporánea de guerras, revoluciones, independencias, corrientes, avances científicos y tecnológicos, se evidencian nuevas formas de pensar y concepciones de valores y del ser humano.

Los tiempos actuales requieren su interpretación, comprensión y reacomodación sin perder la esencia del ser humano. Ahora es necesario iniciar un proceso de intuición e interlocución con actores poco frecuentes: el papel de los jóvenes como actores sociales de trascendencia, las protestas juveniles, el complejo mundo de las drogas, la protesta contra la política y su participación en ella con grandes síntomas de inconformismo social, el amor y la sexualidad han traspasado las fronteras de esta humanidad y sus valores, el enorme problema de la sociedad de consumo-light: ser, poder, tener y placer, la violencia encarnada en el ser humano, entre otros problemas acentuados en la sociedad del siglo XXI en el cual nos corresponde vivir.

\section{Conclusiones}

La ética ha de ocupar un lugar preponderante en la organización del currículo, por ello, en los planes de estudio que por ley se respeta, este espacio se ha de considerar oportuno para despertar en los estudiantes su espíritu humano y social. Se han de considerar varias dificultades en el acto educativo: intensidad horaria, docentes no precisamente todos licenciados en el área, material educativo, compromiso de los estudiantes, entre otros.

El recorrido por la historia en las cuatro grandes épocas permite evidenciar el estatus epistemológico de la ética como disciplina y ciencia inmersa en el quehacer humano. En cada época de la historia, la ética se ha hecho presente según el hombre la ha requerido, por lo que ella exige su presencia o, por el contrario, se ha mantenido al margen y haciendo parte de la indiferencia.

Una nueva tarea de la ética ha especificado su papel como guardiana de la vida humana que se le ha llamado bioética y 
sus problemas: eutanasia, eugenia, aborto, maltrato a animales, entre otros, la cual no se aborda con especificidad en razón de la exigencia de esta y por el compromiso necesario de un fundamento investigativo que la soporte.

\section{REFERENCIAS}

Antolínez Camargo, R. y Gaona, P. F. (1994). Ética y educación: aportes a la polémica sobre los valores. Bogotá, Colombia: Magisterio.

Arango Alzate, O. A. y Meza Rueda, J. L. (2002). El discernimiento y el proyecto de vida: dinamismos para la construcción de sentidos. Bogotá, Colombia: Pontificia Universidad Javeriana.

Blanco, L. (2013). Ética integral. Bogotá, Colombia: ECOE.

Camps Cervera, M. V. (Coord.) (2002a). Historia de la ética. Vol. 1: De los griegos al Renacimiento (2.․ ed.). Barcelona, España: Crítica.

Camps Cervera, M. V. (Coord.) (2002b). Historia de la ética. Vol. 2: La ética moderna (2. a ed.). Barcelona, España: Crítica.

Camps Cervera, M. V. (Coord.) (2002c). Historia de la ética. Vol. 3: La ética contemporánea (2.․ ed.). Barcelona, España: Crítica.

Cantú Martínez, P. C. (2010). Bioética e investigación en salud. Ciudad de México, México: Trillas.

Carreño, M. (1982). Compendio del "Manual de urbanidad y buenas maneras". Bogotá, Colombia: Skla.

Duque, J. (2001). Proyecto de vida (3. ํㅡ ed.). Bogotá, Colombia: Panamericana.
Escobar, G. (1992). Ética: introducción a su problemática y su historia (3. a ed.). Ciudad de México, México: McGraw-Hill.

Escobar, G. (2000). Ética: introducción a su problemática y su historia (4. ․ ed.). Ciudad de México, México: McGraw-Hill.

Esper, M. (2008). Cómo educar en valores éticos. Ciudad de México, México: Trillas.

García, F. y De la Parra F. (1996). Pensemos (2. a ed.). Bogotá, Colombia: Voluntad.

González, L. J. (2003). Ética (3.a ed.). Bogotá, Colombia: El Búho.

Guillén Parra, M. (2005). Ética en las organizaciones: construyendo confianza.Madrid, España: Pearson Educación.

Haydon, H. (2003). Enseñar valores: un nuevo enfoque. Madrid, España: Morata.

Horta Vásquez, E. de J. y Rodríguez Gallón, V. (2006). Ética general. Bogotá, Colombia: ECOE.

Ley 115/1994, de 8 de febrero, por la cual se expide la ley general de educación.

Merchán Price, J. (2012). Ética médica: abusos y atropellos. Bogotá, Colombia: Ediciones de la U.

Michel, G. (1994). Aprende a ser tú mismo. Ciudad de México, México: Trillas.

Morales Ballesteros, H. F. (2002). Filosofía 11: aprendiendo a filosofar con competencias. Bogotá, Colombia: Paulinas.

Morales Ballesteros, H. F. (2006). Filosofía 10: aprendiendo a filosofar con competencias (2.a ed.). Bogotá, Colombia: Paulinas.

Pardo Barrios, I. (2005). Jóvenes contrayente su proyecto de vida (2. ${ }^{\mathrm{a}}$ ed.). Bogotá, Colombia: Magisterio.

Snoek, J. (1998). Ensayo de ética sexual (3 ${ }^{\text {a }}$. ed.). Bogotá, Colombia: San Pablo.

Soto Pineda, E. y Cárdenas, J. A. (2007). Ética en las organizaciones. Ciudad de México, México: McGraw-Hill. 
Suárez, G. (2003). Filosofía I. Bogotá, Colombia: Paulinas.

Riso, W. (1990). Aprendiendo a quererse a sí mismo. Medellín, Colombia: Gráficas.

Rojas López, M. D. (2011). Ética organizacional: estrategias para el éxito. Bogotá, Colombia: Ediciones de la U.
Rozo, E. E. (Comp.) (2001). Tiempo libre, turismo y ética: compendio de las jornadas de reflexión. Bogotá, Colombia: Universidad Externado de Colombia. 